\title{
Thermodynamic Performance of Molten Salt Heat Storage System Used for Regulating Load and Supplying High Temperature Steam in Coal-Fired Cogeneration Power Plants
}

\author{
Haihua Luo ${ }^{1}$, Qiang Shen ${ }^{2}$, Yunfei Chen ${ }^{3, *}$, Shien Sun ${ }^{1}$, Junguang Lin ${ }^{1}$, and Houlei Zhang ${ }^{3}$ \\ ${ }^{1}$ Zhejiang Zheneng Technology Institute, 311100 Hangzhou, China \\ ${ }^{2}$ Zhejiang Zheneng Jiaxing Power Plant Co., Ltd., 314000 Jiaxing, China \\ ${ }^{3}$ School of Energy and Power Engineering, Nanjing University of Science and Technology, 210094 Nanjing, China
}

\begin{abstract}
In order to accept more electricity from renewable energy, cogeneration power plants are considering to reduce electricity production, which affects the heat supply. Here we present a molten salt heat storage system for coal-fired cogeneration power plants, which can supply high temperature steam to users and decouple the heat and electricity production. The first and second law-based analytical models for the cycle and a real device are built. Two water input methods are taken into account. The results show that the high and low temperatures in the two molten salt tanks influence the design of the components and the entropy generation distribution significantly. The pinch temperature difference in the discharge duration limits the lowest molten salt temperature. The device with real heat exchangers produces higher entropy generation and lower second law efficiency. Environmental water input requires more heat and entropy generation for the same steam supply. Recommendations are provided for practical designs.
\end{abstract}

\section{Introduction}

Renewable energy is more and more widely utilized in power generation. Many coal-fired power plants in operation are considering (or required) to reduce their load output in order to accept more electricity from renewable energy $[1,2]$. For cogeneration power plants with coupled electricity and heat outputs, there exist two problems. On one side, the electricity production cannot be dropped too much for ensuring the safety of the equipment and high efficiency. This limits the amount of the acceptable renewable electricity by the grid or the peak regulation capability. On the other side, when the electricity load decreases, the corresponding heat output may not be enough to fulfill the requirement of the heat users. To address these problems, some new operation strategies and new techniques have been explored and studied. Among them, heat storage becomes an attractive option.

Recently, Nuytten et al. [3] reported the flexibility of a combined heat and power system with a water reservoir heat storage for district heating. Garbrecht et al. [4] presented a case study by simulation for two fossil power plants: a heat-controlled waste incinerating facility and a power-controlled sub-critical

lignite power plant. The simulations confirmed the technical feasibility. Li and Wang [5] studied a $600 \mathrm{MW}$ supercritical coal-fired power plant with high temperature salt phase change heat storage. Their simulation results show that the design has faster dynamic response to the load demand changes and the grid frequency services. Zhao et al. [6] compared different flexibility enhancement methods for coal-fired combined heat and power plants and concluded that the design with heat storage has advantages over the heat-only boiler in coal-saving potential and economic performance. Wang et al. [7] investigated the peak shaving range of a heat storagebased unit based on Aspen Plus simulation. The case study of a $300 \mathrm{MW}$ unit shows that the peak regulation capacity is increased significantly. Richter et al. [8] analyzed the effect of a steam accumulator on the load flexibility of coal-fired power plant. The simulation research shows that the load flexibility is improved. Cao et al. [9] proposed an approach for improving load flexibility of coal-fired power plants. High temperature heat storage through additional thermodynamic cycle is incorporated into the conventional system. A mixture of $\mathrm{LiCl}$ and $\mathrm{KCl}$ is selected as the storage material. The case study of a $600 \mathrm{MW}$ supercritical coal-fired power plant shows that the approach is feasible. Up to know, most of the work was simulation-based studies, and high temperature steam supply was not involved.

In this paper, we focus on a cogeneration power plant with molten salt heat storage. Here, the heat is supplied to external industrial users which require higher pressure and temperature than normal building heating, which was

\footnotetext{
* Corresponding author: cyf2388@,njust.edu.cn
} 
not explored in literature. We first describe the configuration of the heat storage system, and then build thermodynamic models for the cycle and a real device. Based on the analytical results, we may determine the thermodynamic performance and identify the irreversibility distribution for the heat storage system which forms the basis of further design optimization.

\section{Configuration of the heat storage system}

Consider a sub-critical cogeneration power plant with industrial steam output to heat users (with pressure $P \sim 1.5$ $\mathrm{MPa}$ and temperature $T \sim 250^{\circ} \mathrm{C}$ ). Figure 1 shows the scheme of the heat storage system for industrial steam supply. In normal mode without the heat storage, the steam at the outlet of the high pressure turbine (State 1) is extracted and its pressure and temperature are reduced through the component $\mathrm{C}$ to the values specified by the users (D). In this process, irreversibility (entropy generation, $S_{g}$, or entropy generation rate $\dot{S}_{g}$ ) is unavoidable. When the electricity load of the power plant is lowered due to the consideration of more timedependent renewable electricity, the heat load may not fulfill the need of the users. As a solution, the heat storage mode works.

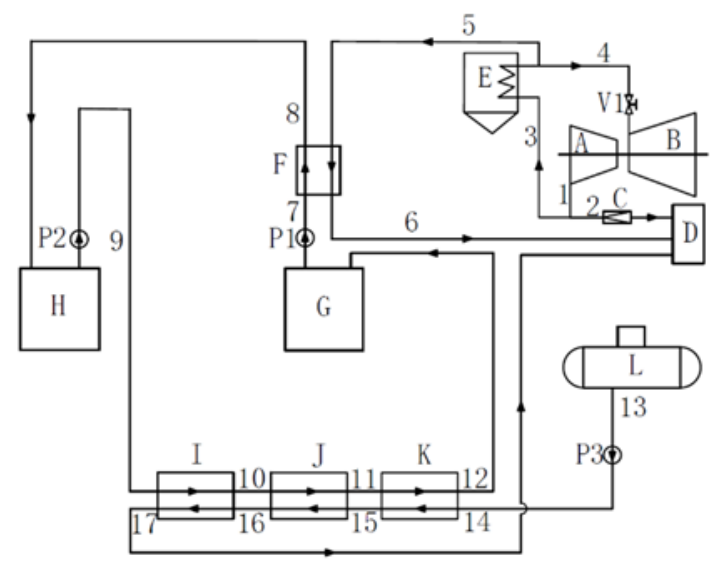

Fig. 1. Heat storage system for industrial steam supply.

(A: High-pressure turbine, B: Medium-pressure turbine, C: Temperature and pressure modulator, D: User, E: Reheater, F: Steam sensible heat exchanger, G: Low temperature $\left(T_{L}\right)$ molten salt tank, H: High temperature $\left(T_{H}\right)$ molten salt tank, I: Superheater, J: Evaporator, K: Preheater, L: Deaerator, P1: Low temperature molten salt pump, P2: High temperature molten salt pump, P3: Water pump, V1: Valve.)

The operation consists of two durations. During the charging duration with time $t_{c}$, the steam at the outlet of the reheater (State 5) is extracted to heat the molten salt from $T_{L}$ (State 7 ) to $T_{H}$ (State 8 ) via the heat exchanger F. The thermal energy is then stored in the high temperature molten salt tank (HTMST). During the discharging duration (usually at night, with time $t_{d}$ ), the hot molten salt in HTMST is driven to heat the water coming from the deaerator (State 13) to the specified state (State 17) via three heat exchangers, i.e., preheater, evaporator and superheater.

Although from the viewpoint of the first law of thermodynamics, the heat storage method does not conserve energy theoretically, it lowers the minimum load of electricity production and ensures the heat supply simultaneously. Heat supply and electricity production are therefore decoupled, and flexible operation becomes available. Besides, the method does not involve the retrofit of the turbines and the boiler, which is an advantage for those old power plants.

Here we use a sub-critical cogeneration power plant as an example. The related parameters are listed in Table 1, where the subscripts correspond to the states in Figure 1.

Table 1. Operation cases.

\begin{tabular}{|c|c|c|c|}
\hline Item & Unit & $\begin{array}{c}\text { Charging } \\
\text { conditions }\end{array}$ & $\begin{array}{c}\text { Discharging } \\
\text { conditions }\end{array}$ \\
\hline $\begin{array}{c}\text { Electricity } \\
\text { load }\end{array}$ & $\mathrm{MW}$ & 205 & 176 \\
\hline$P_{3} / T_{3}$ & $\mathrm{MPa} /{ }^{\circ} \mathrm{C}$ & $2.44 / 319$ & $2.40 / 331$ \\
\hline$P_{5} / T_{5}$ & $\mathrm{MPa} /{ }^{\circ} \mathrm{C}$ & $2.26 / 529$ & $2.20 / 523$ \\
\hline$P_{D} / T_{D}$ & $\mathrm{MPa} /{ }^{\circ} \mathrm{C}$ & $1.43 / 289.76$ & $1.43 / 289.76$ \\
\hline$P_{13} / T_{13}$ & $\mathrm{MPa} /{ }^{\circ} \mathrm{C}$ & $0.52 / 159$ & $0.52 / 159$ \\
\hline
\end{tabular}

\section{Model}

\subsection{Thermodynamic cycle model}

For the thermodynamic cycle analysis, we neglect the heat loss and the pressure drop of the components (the heat exchangers, molten salt tanks and connection pipes). Based on the first and second laws of thermodynamics, the model equations are obtained as follows.

$$
\begin{gathered}
\dot{Q}_{i}=\dot{m}_{h}\left(h_{h i}-h_{h o}\right)=\dot{m}_{c}\left(h_{c o}-h_{c i}\right) \quad i=F, I, J, K \\
\dot{W}_{P j}=\frac{\dot{m}_{P j} \Delta P}{\rho \eta_{P}} \quad j=1,2,3 \\
Q_{\text {total }}=Q_{c}=\dot{Q}_{F} t_{c}=Q_{d}=\left(\dot{Q}_{K}+\dot{Q}_{J}+\dot{Q}_{I}\right) t_{d} \\
Q_{\text {total }}=M_{\text {salt }}\left(h_{9}-h_{12}\right) \\
\eta_{I}=\frac{Q_{d}}{Q_{c}+\left(\dot{W}_{P 2}+\dot{W}_{P 3}\right) t_{d}+\dot{W}_{P 1} t_{c}} \\
\dot{S}_{g i}=\dot{m}_{h}\left(s_{h o}-S_{h i}\right)+\dot{m}_{c}\left(s_{c o}-S_{c i}\right) \quad i=F, I, J, K \\
\dot{S}_{g P j}=\dot{m}_{P j}\left(s_{P j, \text { out }}-S_{P j, i n}\right) \quad j=1,2,3 \\
S_{\text {gtotal }}=S_{g c}+S_{g d}=\dot{S}_{g F} t_{c}+\left(\dot{S}_{g I}+\dot{S}_{g J}+\dot{S}_{g K}+\dot{S}_{g P 3}\right) t_{d}
\end{gathered}
$$




$$
\eta_{I I}=1-\frac{T_{0} S_{\text {gtotal }}}{\left(\dot{E} x_{5}-\dot{E} x_{6}\right) t_{c}+\dot{W}_{P 1} t_{c}+\left(\dot{W}_{P 2}+\dot{W}_{P 3}\right) t_{d}}
$$

In Equations 1-9, $\dot{Q}, \dot{W}$ and $\dot{E} x$ are heat transfer rate, pumping power and exergy rate, respectively; $Q$ is total heat transfer flux in one duration; $\dot{m}$ is mass flow rate; $M$ is mass; $\Delta P$ is pressure drop; $h$ and $s$ are specific enthalpy and entropy; $\eta_{P}(=0.7), \eta_{I}$ and $\eta_{I I}$ are pump efficiency, the first law efficiency and the second law efficiency (i.e., exergy efficiency), respectively; $T_{0}$ represents the surrounding temperature $(298 \mathrm{~K})$. Subscripts $h$ and $c$ represent hot and cold sides, subscripts $i$ and $o$ represent inlet and outlet, and other subscripts correspond to the states or components in Figure 1. In cycle analysis of Section 3.1, as we neglect the pressure drop of the components, $\dot{W}_{P 1}=\dot{W}_{P 2}=0$.

In this paper, HITEC salt $\left(53 \% \mathrm{KNO}_{3}-40 \% \mathrm{NaNO}_{2}-\right.$ $7 \% \mathrm{NaNO}_{3}$, wt $\%$ ) with melting temperature $142^{\circ} \mathrm{C}$ is selected as the heat storage material and the heat transfer fluid with temperature-dependent properties [10, 11]. An EES (Engineering Equation Solver) program is compiled to solve the above model. The properties of water are calculated by EES.

\subsection{Steady device model}

In this section, we analyse a case study with real heat exchangers under the specified conditions: $T_{H}=420^{\circ} \mathrm{C}, T_{L}$ $=190^{\circ} \mathrm{C}$ and total heat load $Q_{\text {total }}=350.5 \mathrm{MWh}$. The temperature at State 6 is kept the same as that in the cycle analysis. ASPEN EDR software [12] is used to design the heat exchangers. All four heat exchangers are U-type shell-and-tube structure considering thermal stress and expansion. For simplicity, we deal with the molten salt tanks and the connection pipes as two equivalent pipes, one for charging loop of molten salt (Pipe 1), and another for discharging loop of molten salt (Pipe 2). The pressure drops of Pipe 1 and Pipe 2 are assumed empirically. The entropy generation rate for an equivalent pipe is calculated by:

$$
\dot{S}_{g, \text { Pipek }}=\dot{m}_{\text {Pipek }}\left(s_{\text {Pipek }, \mathrm{o}}-S_{\text {Pipek }, \mathrm{i}}\right) \quad k=1,2
$$

Then we obtain

$$
\begin{gathered}
S_{g c}=\left(\dot{S}_{g F}+\dot{S}_{g P 1}+\dot{S}_{g, P \text { Pipe } 1}\right) t_{c} \\
S_{g d}=\left(\dot{S}_{g l}+\dot{S}_{g J}+\dot{S}_{g K}+\dot{S}_{g P 2}+\dot{S}_{g P 3}+\dot{S}_{g, P \text { Pipe } 2}\right) t_{d} \\
S_{\text {gtotal }}=S_{g c}+S_{g d}
\end{gathered}
$$

Here Equations 11-13 replace Equation 8 in the cycle analysis.

The effect of the pressure drop of the heat exchangers on entropy generation has been included in Equation 6. The power consumption of the two molten salt pumps (not zero now) is calculated by Equation 2. Similar to Section 3.1, an EES program is compiled to calculate the thermodynamic performance with the pressure drop of the components taken into account.

\section{Results and discussion}

\subsection{Thermodynamic cycle analysis}

We start the cycle analysis from $T_{H}=420^{\circ} \mathrm{C}$ and $T_{L}=190^{\circ} \mathrm{C}$ for specified heating load $Q_{\text {total }}=350.5 \mathrm{MWh}$ and fixed $t_{c}$ $=18 \mathrm{~h}$ and $t_{d}=6 \mathrm{~h}$. The cycle analysis results are shown in Table 2. We see that the evaporator $\mathrm{J}$ absorbs much more heat than I and $\mathrm{K}$, and also produces more entropy generation rate. The second law efficiency $\eta_{I I}$ is significantly lower than the first law efficiency $\eta_{I}$.

Table 2. Cycle analysis results.

\begin{tabular}{|l|l|l|l|l|l|}
\hline Item & Unit & Value & Item & Unit & Value \\
\hline$T_{H}$ & ${ }^{\circ} \mathrm{C}$ & 420 & $\dot{Q}_{J}$ & $\mathrm{MW}$ & 48.24 \\
\hline$T_{L}$ & ${ }^{\circ} \mathrm{C}$ & 190 & $\dot{Q}_{K}$ & $\mathrm{MW}$ & 4.61 \\
\hline$T_{6}$ & ${ }^{\circ} \mathrm{C}$ & 289.76 & $Q_{\text {total }}$ & $\mathrm{MWh}$ & 350.5 \\
\hline$T_{10}$ & ${ }^{\circ} \mathrm{C}$ & 395.5 & $\dot{W}_{P 3}$ & $\mathrm{~kW}$ & 35.24 \\
\hline$T_{11}$ & ${ }^{\circ} \mathrm{C}$ & 205.7 & $\dot{S}_{g F}$ & $\mathrm{~kW} / \mathrm{K}$ & 5.59 \\
\hline$T_{15}$ & ${ }^{\circ} \mathrm{C}$ & 196.1 & $\dot{S}_{g I}$ & $\mathrm{~kW} / \mathrm{K}$ & 2.67 \\
\hline$T_{16}$ & ${ }^{\circ} \mathrm{C}$ & 196.1 & $\dot{S}_{g J}$ & $\mathrm{~kW} / \mathrm{K}$ & 17.35 \\
\hline$\dot{m}_{5}$ & $\mathrm{t} / \mathrm{h}$ & 130.1 & $\dot{S}_{g K}$ & $\mathrm{~kW} / \mathrm{K}$ & 0.50 \\
\hline$\dot{m}_{7}$ & $\mathrm{t} / \mathrm{h}$ & 152.7 & $\dot{S}_{g P 3}$ & $\mathrm{~kW} / \mathrm{K}$ & 0.02 \\
\hline$\dot{m}_{9}$ & $\mathrm{t} / \mathrm{h}$ & 458.2 & $S_{g c}$ & $\mathrm{MJ} / \mathrm{K}$ & 362.1 \\
\hline$\dot{m}_{13}$ & $\mathrm{t} / \mathrm{h}$ & 88.81 & $S_{g d}$ & $\mathrm{MJ} / \mathrm{K}$ & 443.7 \\
\hline$\dot{Q}_{F}$ & $\mathrm{MW}$ & 19.47 & $S_{g t o t a l}$ & $\mathrm{MJ} / \mathrm{K}$ & 805.8 \\
\hline$\dot{Q}_{I}$ & $\mathrm{MW}$ & 5.58 & $\eta_{I I}$ & $\%$ & 65.92 \\
\hline$\eta_{I}$ & $\%$ & 99.94 & & & \\
\hline
\end{tabular}

Figure 2 shows the effects of $T_{H}$ on the cycle performance. In Figure 2a, the two molten salt flow rates $\dot{m}_{7}$ and $\dot{m}_{9}$ decrease with the increase of $T_{H}$, which requires smaller molten salt pumps. Another advantage of higher $T_{H}$ is less molten salt mass $\left(M_{\text {salt }}\right)$, which corresponds to larger heat storage density or smaller molten salt tank size (or investment). When $T_{H}$ increases, the average temperature difference of the heat exchanger $\mathrm{F}$ decreases and larger heat transfer area is required. Figure $2 \mathrm{~b}$ documents the entropy generation of $\mathrm{F}, \mathrm{I}, \mathrm{J}, \mathrm{K}$ and P3. With the increase of $T_{H}$, the entropy generation rate of F drops, while $\dot{S}_{g I}, \dot{S}_{g J}$ and $\dot{S}_{g K}$ increase very slightly. We also see that the irreversibility of the water pump is small. Figure $2 \mathrm{c}$ shows the variation of the irreversibility distribution between the charging duration and the discharging duration. To summarize, $T_{H}$ affects both the design of the components and the irreversibility distribution, but does not change $\eta_{I}$ and $\eta_{I I}$. 


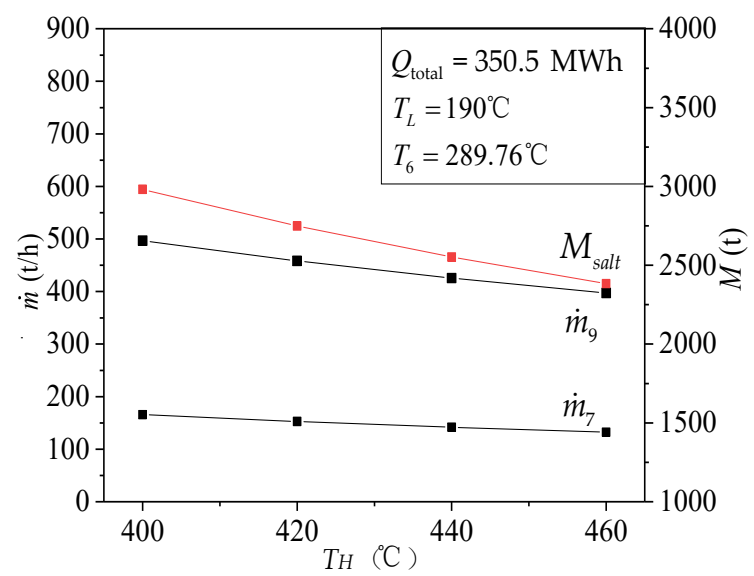

(a)

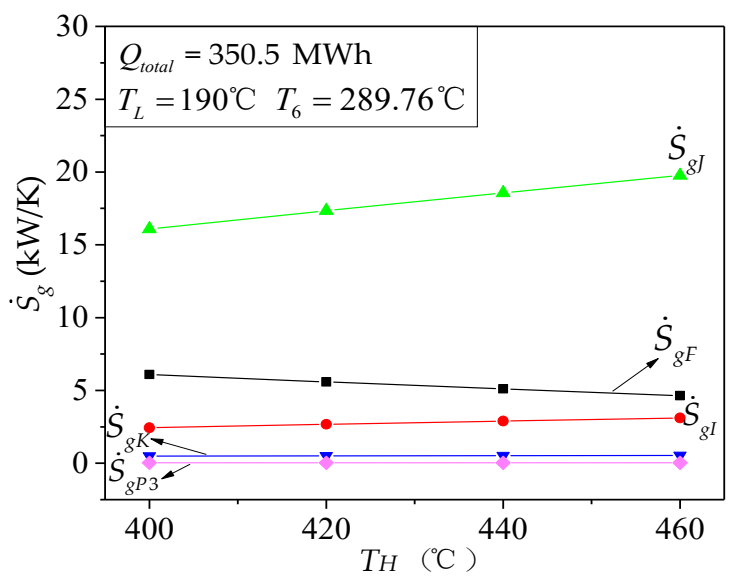

(b)

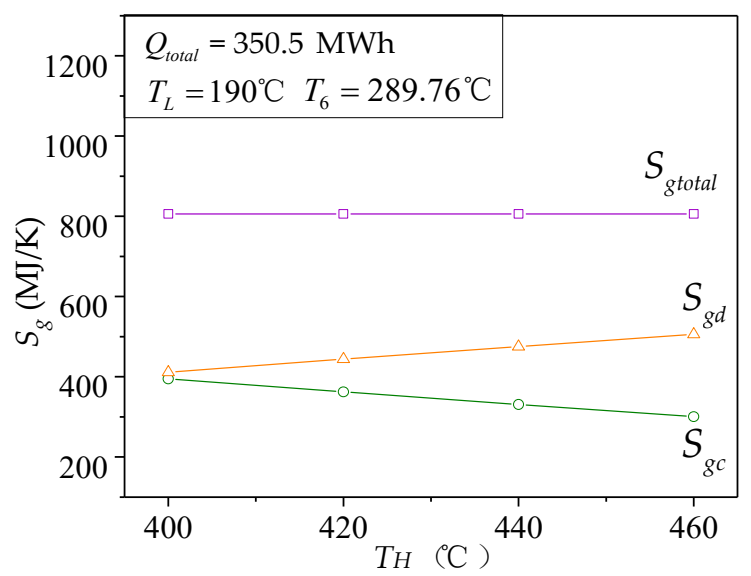

(c)

Fig. 2. The effects of $T_{H}$ on cycle performance.

Figure 3 shows the effects of $T_{L}$ on the cycle performance. Seen in Figure 3a, with the decrease of $T_{L}$, the flow rates $\dot{m}_{7}$ and $\dot{m}_{9}$ and the molten salt mass $M_{\text {salt }}$ decrease, similar to the influence of increasing $T_{H}$. From Figure $3 b$, we see the variation of $\dot{S}_{g F}, \dot{S}_{g I}, \dot{S}_{g J}$ and $\dot{S}_{g K}$ with $T_{L}$, while the total entropy generation rate $S_{\text {gtotal }}$ keeps constant (Figure 3c). Same as $T_{H}, T_{L}$ does not influence $\eta_{I}$ and $\eta_{I I}$. In brief, $\left(T_{H}-T_{L}\right)$ affects the design or selection of the heat exchangers and the pumps, as well as the entropy generation distribution. Another point in selecting $T_{L}$ is the limitation of pinch temperature difference between State 11 and State $15\left(\Delta T_{11-15}\right)$. One case is shown in Figure 4, where $\Delta T_{11-15}=9.6^{\circ} \mathrm{C}$. If we set $\Delta T_{11-15}=5^{\circ} \mathrm{C}$, the lowest $T_{L}$ will be $185.1^{\circ} \mathrm{C}, 182.6^{\circ} \mathrm{C}$ and $180.1^{\circ} \mathrm{C}$ for $T_{H}=420^{\circ} \mathrm{C}, 460^{\circ} \mathrm{C}$ and $500^{\circ} \mathrm{C}$, respectively. In real designs, trade-off or optimization is necessary considering both the cost of the heat exchangers and that of the molten salt tanks.

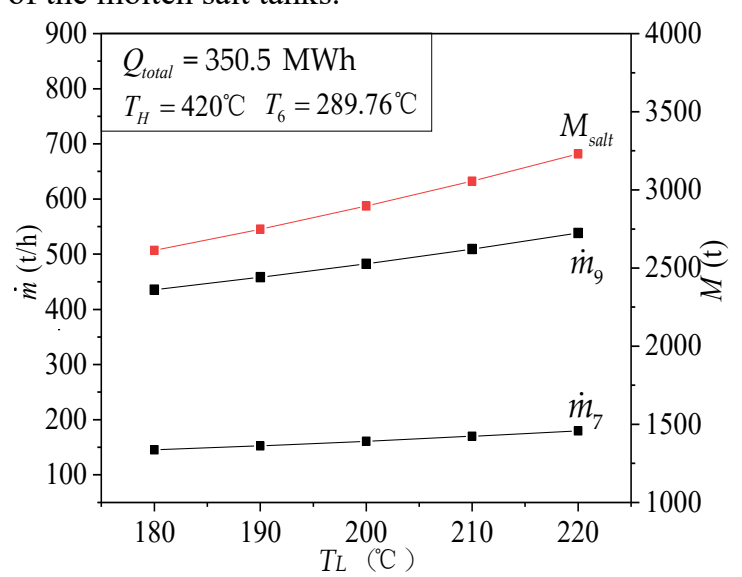

(a)

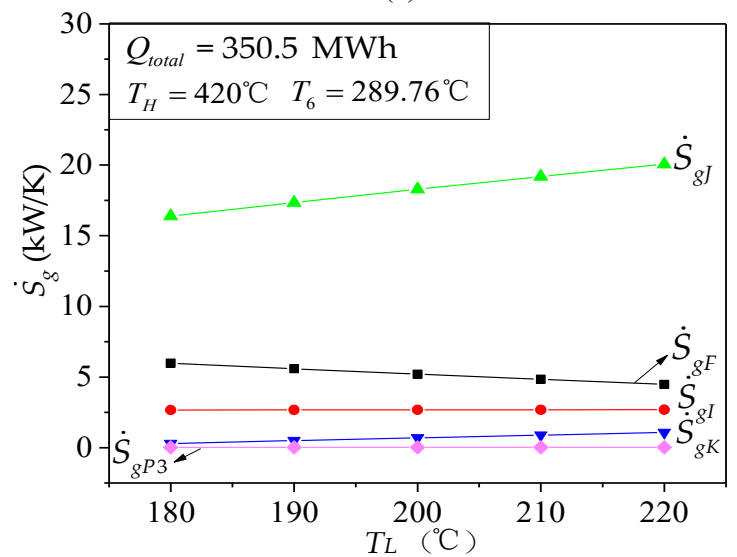

(b)

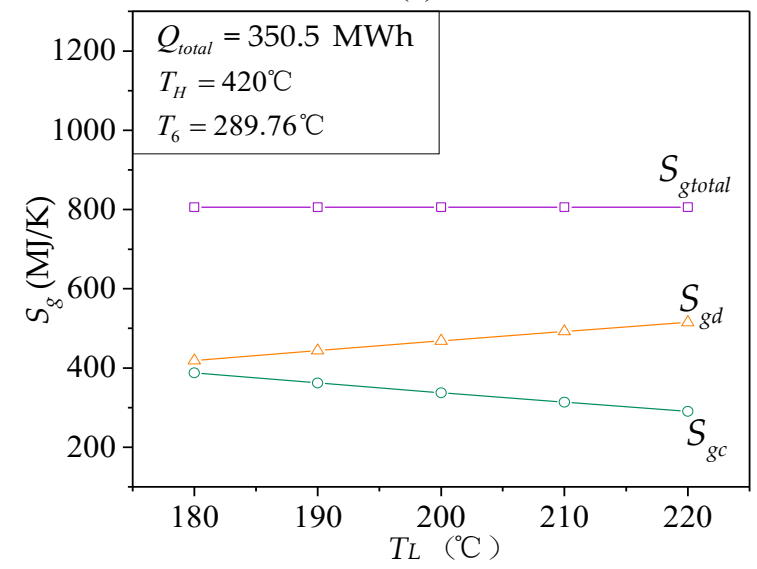

(c)

Fig. 3. The effects of $T_{L}$ on cycle performance.

Table 3 shows the cycle analysis results with environmental water input, i.e., $T_{0}\left(=25^{\circ} \mathrm{C}\right)$ instead of $T_{13}$ $\left(=159^{\circ} \mathrm{C}\right)$. In this case, the water input is decoupled from the power plant. For the same steam supply $\dot{m}_{13}$ $88.81 \mathrm{t} / \mathrm{h}$ ), both $Q_{\text {total }}$ and $S_{\text {gtotal }}$ increase. Because of lower water input temperature at the inlet the preheater $\mathrm{K}$, the overall second law efficiency drops from $65.92 \%$ (in 
Table 2) to $59.32 \%$ (in Table 3), while the first law efficiency is nearly constant.

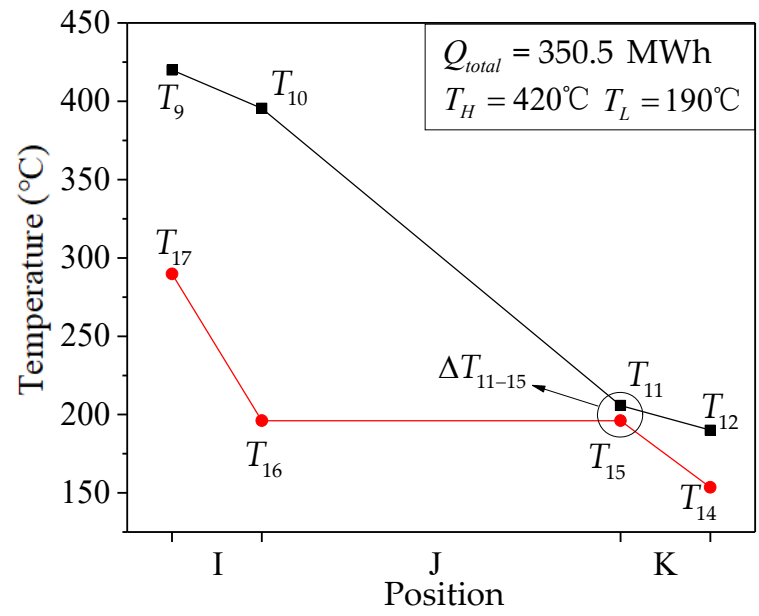

Fig. 4. Pinch temperature difference $\Delta T_{11-15}\left(=9.6^{\circ} \mathrm{C}\right)$.

Table 3. Cylce analysis with environmenal water input.

\begin{tabular}{|l|l|l|l|l|l|}
\hline Item & Unit & Value & Item & Unit & Value \\
\hline$T_{H}$ & ${ }^{\circ} \mathrm{C}$ & 420 & $\dot{Q}_{J}$ & $\mathrm{MW}$ & 48.24 \\
\hline$T_{L}$ & ${ }^{\circ} \mathrm{C}$ & 190 & $\dot{Q}_{K}$ & $\mathrm{MW}$ & 17.95 \\
\hline$T_{6}$ & ${ }^{\circ} \mathrm{C}$ & 289.76 & $Q_{\text {total }}$ & $\mathrm{MWh}$ & 430.6 \\
\hline$T_{10}$ & ${ }^{\circ} \mathrm{C}$ & 400 & $\dot{W}_{P 3}$ & $\mathrm{~kW}$ & 51.51 \\
\hline$T_{11}$ & ${ }^{\circ} \mathrm{C}$ & 241.2 & $\dot{S}_{g F}$ & $\mathrm{~kW} / \mathrm{K}$ & 6.87 \\
\hline$T_{15}$ & ${ }^{\circ} \mathrm{C}$ & 196.1 & $\dot{S}_{g I}$ & $\mathrm{~kW} / \mathrm{K}$ & 2.7 \\
\hline$T_{16}$ & ${ }^{\circ} \mathrm{C}$ & 196.1 & $\dot{S}_{g J}$ & $\mathrm{~kW} / \mathrm{K}$ & 20.72 \\
\hline$\dot{m}_{5}$ & $\mathrm{t} / \mathrm{h}$ & 159.9 & $\dot{S}_{g K}$ & $\mathrm{~kW} / \mathrm{K}$ & 10.66 \\
\hline$\dot{m}_{7}$ & $\mathrm{t} / \mathrm{h}$ & 187.6 & $\dot{S}_{g P 3}$ & $\mathrm{~kW} / \mathrm{K}$ & 0.06 \\
\hline$\dot{m}_{9}$ & $\mathrm{t} / \mathrm{h}$ & 562.9 & $S_{g c}$ & $\mathrm{MJ} / \mathrm{K}$ & 444.9 \\
\hline$\dot{m}_{13}$ & $\mathrm{t} / \mathrm{h}$ & 88.81 & $S_{g d}$ & $\mathrm{MJ} / \mathrm{K}$ & 737.3 \\
\hline$\dot{Q}_{F}$ & $\mathrm{MW}$ & 23.92 & $S_{g t o t a l}$ & $\mathrm{MJ} / \mathrm{K}$ & 1182 \\
\hline$\dot{Q}_{I}$ & $\mathrm{MW}$ & 5.58 & $\eta_{I I}$ & $\%$ & 59.32 \\
\hline$\eta_{I}$ & $\%$ & 99.93 & & & \\
\hline
\end{tabular}

\subsection{Steady device analysis}

Section 4.1 does not involve the structure and size (or the design) of the heat exchangers. Here for specified heating load $Q_{\text {total }}=350.5 \mathrm{MWh}$, we select $T_{H}=420^{\circ} \mathrm{C}$ and $T_{L}=$ $190^{\circ} \mathrm{C}$ in the device design to perform a case study. Usually, when the temperature is lower than $420^{\circ} \mathrm{C}$, carbon steel can be used in the heat exchangers I, J and $\mathrm{K}$ and the two molten salt tanks, which will save equipment investment apparently compared with more expensive materials, like stainless steel used for the heat exchanger F. The temperature $T_{L}=190^{\circ} \mathrm{C}$ considers the temperature tolerance to avoid the risk of salt solidification and acceptable pinch temperature difference. The temperature tolerance is relevant to the operation program (e.g., shutdown period) and the insulation performance (or heat loss) of the molten salt tanks. The parameters of the four heat exchangers are given in Table 4 . The pressure drops of Pipe 1 and Pipe 2 are adopted as $0.2 \mathrm{MPa}$ approximately.
Table 4. Design of heat exchangers.

\begin{tabular}{|l|l|l|l|l|}
\hline Heat exchanger & F & I & J & K \\
\hline Type & \multicolumn{5}{|c|}{ BEU } \\
\hline Material & SS 347 & \multicolumn{3}{|c|}{ Carbon Steel } \\
\hline Shell OD /mm & 1000 & 800 & 1800 & 800 \\
\hline Tube OD /mm & \multicolumn{5}{|c|}{25} \\
\hline Tube length /m & 3 & 1.5 & 6 & 4 \\
\hline No. of tubes & 1400 & 900 & 2200 & 400 \\
\hline Tube arrangement & \multicolumn{5}{|c|}{$30^{\circ}$} \\
\hline Baffle & \multicolumn{5}{|c|}{$25 \%$} \\
\hline Baffle cut & \multicolumn{5}{|c|}{400} & 520 & 300 \\
\hline Baffle spacing $/ \mathrm{mm}$ & 300 & \multicolumn{5}{|c|}{40 gmental } \\
\hline Shells in series & 2 & 1 & 1 & 2 \\
\hline No. of passes & 2 & 2 & 4 & 4 \\
\hline Area/m ${ }^{2}$ & 695 & 115.6 & 1099.4 & 263.1 \\
\hline
\end{tabular}

Table 5 shows a case study with real heat exchangers and assumed pressure drops of the tanks and connection pipes. Both $\eta_{I}$ and $\eta_{I I}$ of the device are lower than that of the cycle without considering the pressure drops of the components. The total entropy generation of the device is $12.3 \%$ higher than that of the cycle. The entropy generation distribution has slight change compared with that in the cycle analysis. It should be noted that although we take the real heat exchangers into account, the heat loss of the components is neglected. The analysis for the device is still approximate.

Table 5. A case study with real heat exchangers.

\begin{tabular}{|l|l|l|l|l|l|}
\hline Item & Unit & Value & Item & Unit & Value \\
\hline$T_{H}$ & ${ }^{\circ} \mathrm{C}$ & 420 & $\dot{Q}_{J}$ & $\mathrm{MW}$ & 48.00 \\
\hline$T_{L}$ & ${ }^{\circ} \mathrm{C}$ & 190 & $\dot{Q}_{K}$ & $\mathrm{MW}$ & 4.87 \\
\hline$T_{6}$ & ${ }^{\circ} \mathrm{C}$ & 289.76 & $Q_{\text {total }}$ & $\mathrm{MWh}$ & 350.5 \\
\hline$T_{10}$ & ${ }^{\circ} \mathrm{C}$ & 395.8 & $\dot{S}_{g F}$ & $\mathrm{~kW} / \mathrm{K}$ & 7.00 \\
\hline$T_{11}$ & ${ }^{\circ} \mathrm{C}$ & 206.7 & $\dot{S}_{g I}$ & $\mathrm{~kW} / \mathrm{K}$ & 3.02 \\
\hline$T_{15}$ & ${ }^{\circ} \mathrm{C}$ & 198.5 & $\dot{S}_{g J}$ & $\mathrm{~kW} / \mathrm{K}$ & 17.02 \\
\hline$T_{16}$ & ${ }^{\circ} \mathrm{C}$ & 197.8 & $\dot{S}_{g K}$ & $\mathrm{~kW} / \mathrm{K}$ & 0.50 \\
\hline$\dot{m}_{5}$ & $\mathrm{t} / \mathrm{h}$ & 131.56 & $\dot{S}_{g P 1}$ & $\mathrm{~kW} / \mathrm{K}$ & 0.006 \\
\hline$\dot{m}_{7}$ & $\mathrm{t} / \mathrm{h}$ & 152.7 & $\dot{S}_{g P 2}$ & $\mathrm{~kW} / \mathrm{K}$ & 0.03 \\
\hline$\dot{m}_{9}$ & $\mathrm{t} / \mathrm{h}$ & 458.2 & $\dot{S}_{g P 3}$ & $\mathrm{~kW} / \mathrm{K}$ & 0.027 \\
\hline$\dot{m}_{13}$ & $\mathrm{t} / \mathrm{h}$ & 88.81 & $\dot{S}_{g c, p i p e}$ & $\mathrm{~kW} / \mathrm{K}$ & 0.047 \\
\hline$\dot{W}_{P I}$ & $\mathrm{~kW}$ & 3.23 & $\dot{S}_{g d, p i p e}$ & $\mathrm{~kW} / \mathrm{K}$ & 0.152 \\
\hline$\dot{W}_{P 2}$ & $\mathrm{~kW}$ & 26.23 & $S_{g c}$ & $\mathrm{MJ} / \mathrm{K}$ & 456.9 \\
\hline$\dot{W}_{P 3}$ & $\mathrm{~kW}$ & 38.56 & $S_{g d}$ & $\mathrm{MJ} / \mathrm{K}$ & 448.2 \\
\hline$\dot{Q}_{F}$ & $\mathrm{MW}$ & 19.47 & $S_{g t o t a l}$ & $\mathrm{MJ} / \mathrm{K}$ & 905.1 \\
\hline$\dot{Q}_{I}$ & $\mathrm{MW}$ & 5.55 & $\eta_{I I}$ & $\%$ & 63.2 \\
\hline$\eta_{I}$ & $\%$ & 99.87 & & & \\
\hline
\end{tabular}

\section{Conclusions}

In this paper, we presented the thermodynamic performance of molten salt heat storage system for coal- 
fired cogeneration power plants, which can supply high temperature steam to users and decouple the heat and electricity production. The total entropy generation and the irreversibility distribution are documented. The two molten salt temperatures $\left(T_{H}\right.$ and $\left.T_{L}\right)$ influence the design of the components and the entropy generation distribution, and proper parameters are recommended. The pinch temperature difference in the discharge duration is also discussed, which, as well as the solidification temperature of the molten salt, limits the lowest $T_{L}$. A case study with real heat exchangers is performed, which corresponds to higher entropy generation and lower second law efficiency. Instead of supplying water from the deaerator, environmental water input is also possible, which requires more heat and entropy generation for the same steam supply.

It should be reminded that the present work only focuses on the heat storage part itself, and does not evaluate the comprehensive influence of the incorporation of the heat storage on the overall power plant, which is the future work of us.

\section{References}

1. Z. Wang, Y. Zhu, Y. Zhu, Y. Shi, Energy 115, 369377 (2016).

2. J. Kopiske, S. Spieker, G. Tsatsaronis, Energy 137, 823-833 (2017).

3. T. Nuytten, B. Claessens, K. Paredis, J. Van Bael, D. Six, Appl. Energy 104, 583-591 (2013).

4. O. Garbrecht, M. Bieber, R. Kneer, Energy 118, 876883 (2017).

5. D. Li, J. Wang, J. Energy Storage 20, 140-152 (2018).

6. S. Zhao, Z. Ge, J. Sun, Y. Ding, Y. Yang, Energy Convers. Manage. 184, 15-23 (2019).

7. H. Wang, X. Dong, J. Yang, T. Luo, J. Turbine Technology 61, 54-58 (2019).

8. M. Richter, G. Oeljeklaus, K. Görner, Appl. Energy 236, 607-621 (2019).

9. R. Cao, Y. Lu, D. Yu, Y. Guo, W. Bao, Z. Zhang, C. Yang, Appl. Therm. Eng. 173, 115-225 (2020).

10. M. S. Sohal, M. A. Ebner, P. Sabharwall, P. Sharpe, Engineering Database of Liquid Salt Thermophysical and Thermochemical Properties. (Idaho National Laboratory, Idaho Falls, U.S.A, 2010)

11. R. Tufeu, J. P. Petitet, L. Denielou, B. Le Neindre, Int. J. Thermophys. 6, 315-330 (1985).

12. L. Sun, Thermal Design of Heat Exchangers (China Petrochemical Press Co., Ltd, Beijing, China, 2015) 